\title{
Safer Tripping: Serotonergic Psychedelics and Drug Checking. Submission and Detection Rates, Potential Harms, and Challenges for Drug Analysis
}

\author{
Tim Hirschfeld $^{1}$ (D) $\cdot$ Laura Smit-Rigter $^{2} \cdot$ Daan van der Gouwe $^{2} \cdot$ Simon Reiche $^{1} \cdot$ Heino Stöver $^{3} \cdot$ Tomislav Majić $^{1,4}$
}

Accepted: 14 May 2021 / Published online: 27 July 2021

(C) The Author(s) 2021

\begin{abstract}
Purpose of Review With the continuous emergence of new psychoactive substances, drug checking (DC) services are challenged by an increasingly complex drug market. Considering the resumed scientific and public interest in serotonergic psychedelics (SPs) like LSD, psilocybin, and 2C-B, we present the results of a literature search investigating the presence and proportion of SPs in DC samples.

Recent Findings In 15 identified reports, submission and detection rates of SPs were comparably low, but increasing. Samples contained considerable amounts of adulterations or analogues, mostly novel SPs with unknown toxicological profiles and in some cases potentially life-threatening effects. The detection of SPs, however, requires advanced analysis techniques currently not available to most DC services.

Summary Given the substantial proportion of novel SPs in DC samples and the associated risks, DC can be a valuable harm reduction and monitoring tool for SPs if analysis techniques with high sensitivity are employed.
\end{abstract}

Keywords Serotonergic psychedelics $\cdot$ New psychoactive substances $\cdot$ NBOMes $\cdot$ Drug checking $\cdot$ Harm reduction $\cdot$ Drug monitoring

\section{Introduction}

Drug checking (DC) is a harm reduction tool and a drug market monitoring measure that enables potential substance users to anonymously submit samples of substances they intend to use

Tim Hirschfeld

tim.hirschfeld@charite.de

1 Research Group Psychotropic Substances, Psychiatric University Clinic at Hospital St. Hedwig, Charité Universitätsmedizin Berlin, Berlin, Germany

2 Drugs Information and Monitoring System, Department of Drug Monitoring and Policy, Trimbos Institute, Utrecht, The Netherlands

3 Department of Health and Social Work, Institute of Addiction Research, Frankfurt University of Applied Sciences, Frankfurt/ Main, Germany

4 Berlin Institute of Health, Charité Universitätsmedizin Berlin, Corporate Member of Freie Universität Berlin, Humboldt-Universität zu Berlin, Campus Charité Mitte, Berlin, Germany for chemical analysis [1]. By combining fact-based information on the composition of substances with a consultative talk provided by a trained staff, DC has shown to prevent adverse health effects in generally hard-to-reach groups of users who are ambiguous about consulting conventional substance use support services [1-4]. Additionally, awareness can be raised regarding associated health risks of the detected compound(s), harm minimisation strategies, harmful substance use patterns, and, if requested, low-threshold referral to treatment programmes $[5,6]$. Furthermore, DC has also proven to be a valuable tool for monitoring recreationally used substances from unregulated markets and for disseminating public warning campaigns in a factual and timely manner $\left[7^{\circ}\right]$, e.g. as part of the EU Early Warning System on new psychoactive substances (NPS) [8]. In 2017, 29 DC organisations operated in 20 countries, with the Dutch Drugs Information and Monitoring System (DIMS) being one of the oldest $\left[7^{\circ}, 9\right]$.

Originally, the majority of samples submitted to DC services contained stimulants used in party settings, namely MDMA (ecstasy), amphetamine, and cocaine [5]. However, 
the illicit substance market has become more complex in terms of variety and combination of substances used [10]. Therefore, DC services have been required to detect and monitor evermore substances, which is often limited by the available analysis techniques $[11,12]$. Along with the renewed scientific interest in the therapeutic potential of serotonergic psychedelics (SPs) like LSD, psilocybin (4-phosphoryloxy$\mathrm{N}, \mathrm{N}$-dimethyltryptamine in "magic mushrooms"), and ayahuasca [13], reports also indicate a comparably low but increasing recreational use of SPs in recent years [14-20].

SPs share agonist action at type 2A serotonin (5-HT2a) receptors as the main mechanism of action for psychedelic effects [21]. Classic SPs include substances like LSD, psilocybin, DMT, and mescaline, with LSD still being the most commonly used SP worldwide, a semi-synthetic compound that has pharmacologically been intensively investigated with regard to its pharmacological [22] and psychoactive [23] properties. Other classic SPs like psilocybin, DMT, and mescaline are naturally occurring substances with a relatively long history of human usage [24]. More recently, however, a variety of novel synthetic SPs has emerged, labelled as NPS. Per definition, NPS are substances that are not controlled by the 1961 Single Convention on Narcotic Drugs or the 1971 Convention on Psychotropic Substances [25]. In contrast to the classic SPs, the pharmacological and toxicological properties of most of these novel substances are widely unknown, leading to unpredictable risks when used intendedly or unintendedly.

As shown in Fig. 1, SPs can structurally be categorised into three main chemical types of 5-HT2a agonists: tryptamines (e.g. psilocybin, DMT), which are found in fungi, plants, and animals [26] and most closely resemble the natural neurotransmitter serotonin [27]; lysergamides (e.g. LSD, ALLAD), which can be considered to be rigidified tryptamines [27] derived from alkaloids produced by the ergot fungus; and psychedelic phenethylamines, of which mescaline is its only naturally occurring psychedelic compound $[22,28]$. While all groups comprise both classic and novel SPs, the variety of novel SPs is particularly pronounced in the phenethylamine group due to the comparably easy synthesisation and the large amount of possible modifications [28]. Therefore, phenethylamines can be further divided into substituted 2,5dimethoxy-amphetamine derivatives (DOx, e.g. DOB), substituted 2,5-dimethoxy-phenethylamine derivatives (2Cx, e.g. 2C-B), and the more recently emerged N-benzylated derivatives of $2 \mathrm{C}-\mathrm{x}$ (NBOMes, e.g. 25I-NBOMe) [29, 30] (see list of abbreviations). Interestingly, participants in early studies failed to discriminate between the subjective experience of the tryptamine psilocybin, the lysergamide LSD, and the phenethylamine mescaline [31,32]; however, quantitative data obtained from experience reports [33] and validated psychometric instruments indicate slight differences [23, 34].

Besides their addictive potential, the use of stimulants, opioids, and other substances is predominantly associated with physical risks, i.e. toxicity related to unknown quantity (i.e. the actual dosage) and purity (i.e. adulterations or analogues). In contrast, SPs are generally not associated with addictive properties, and their acute risks are rather of a psychological nature $\left[35^{\circ}\right]$. However, given the large number of NPS that emerge every year [36, 37], novel SPs like NBOMes may become an increasing public health concern, as they have resulted in numerous cases of health-related incidents and fatalities [38, 39].

Given the aforementioned recently increased interest in SPs use, the continuous emergence of novel SPs, and the potential psychological harms associated with recreational SPs use, the aim of the present review was to find out which relevance SPs have in currently operating DC services. Therefore, we investigate the presence and proportion of SPs in submitted DC samples as well as the adulterations and analogues of SPs found in submitted DC samples. In addition, we discuss what physical and psychological harms are associated with SPs detected by DC services and what challenges are associated with their detection.

\section{Methods}

To investigate the presence and proportion of SPs, as well as their adulterations and analogues in recent DC samples, we performed a literature search in PubMed (MEDLINE) using the terms "drug checking" OR "pill testing" OR "drug safety testing". Additionally, hand-searched references of retrieved articles and Google Scholar were screened. We included peerreviewed articles published between January 1980 and March 2021 in English, Dutch, or German, which provide original information on submission or detection of SPs by international DC services.

\section{Results on Serotonergic Psychedelics in Submitted Drug Checking Samples}

The search strategy in PubMed (MEDLINE) yielded 184 database records, of which 14 records contained original information on submission or DC of SPs by drug checking services. One additional report was identified via additional manual search [40]. All 15 reports we included were published in English from 2005 onward, providing information for the Netherlands, Spain, UK, Italy, Portugal, Belgium, Canada, and Australia.

\section{The Netherlands}

Hondebrink et al. investigated the NPS prevalence rates in forensic samples and poison centre data from the Dutch Poisons Information Centre as well as in DC samples 
A<smiles>NCCc1c[nH]c2ccccc12</smiles>

Tryptamine<smiles>NCCc1c[nH]c2ccc(O)cc12</smiles>

Serotonin<smiles>CN(C)CCc1c[nH]c2cccc(O)c12</smiles>

Psilocin<smiles>CN(C)CCc1c[nH]c2ccccc12</smiles>

DMT<smiles>CC(N)Cc1c[nH]c2ccccc12</smiles>

AMT<smiles>CCN(C)CCc1c[nH]c2cccc(O)c12</smiles>

4-HO-MET<smiles>COc1ccc2[nH]cc(CCN(C)C(C)C)c2c1</smiles>

5-MeO-MiPT<smiles>CC(=O)Oc1cccc2[nH]cc(CCN(C)C)c12</smiles>

4-AcO-DMT

B<smiles>CN1CC(C(N)=O)C=C2c3cccc4[nH]cc(c34)C[C@]21C</smiles>

Lysergamide<smiles>CCN(CC)C(=O)[C@@H]1C=C2c3cccc4[nH]cc(c34)C[C@H]2N(C)C1</smiles>

LSD<smiles>CCC(=O)n1cc2c3c(cccc31)C1=C[C@@H](C(=O)N(CC)CC)CN(C)[C@H]1C2</smiles>

1P-LSD<smiles>C=CCN1C[C@H](C(=O)N(CC)CC)C=C2c3cccc4[nH]cc(c34)C[C@H]21</smiles>

AL-LAD

\section{C}<smiles>NCCc1ccccc1</smiles>

Phenethylamine<smiles>COc1cc(CC(C)N)c(OC)cc1C</smiles>

DOM<smiles>COc1cc(CCN)cc(OC)c1OC</smiles>

Mescaline<smiles>COc1cc(CC(C)N)c(OC)cc1I</smiles>

$\mathrm{DOI}$<smiles>COc1cc(CCN)c(OC)cc1Br</smiles>

$2 \mathrm{C}-\mathrm{B}$<smiles>CC(N)Cc1c2ccoc2c(Br)c2ccoc12</smiles>

Bromo-DragonFLY<smiles>COc1cc(CCNCc2ccccc2OC)c(OC)cc1Br</smiles>

25B-NBOMe<smiles>COc1cc(CCNCc2ccccc2OC)c(OC)cc1I</smiles>

Fig. 1 Chemical structures of the main classes of serotonergic psychedelics and examples of their derivatives, including the neurotransmitter serotonin. A Tryptamine and its derivatives: serotonin, psilocin (4-hydroxy-N,N-dimethyltryptamine; dephosphorylated psilocybin), DMT, AMT, 4-HO-MET, 5-MeO-MIPT, and 4-AcO-

submitted to DIMS between 2007-2013 [40] and 2013-2017 [41"*]. The authors stated that the number of NPS in submitted samples had increased over the last decade despite considerable annual variations. While NPS were found in $0.5 \%$ of

DMT. B Lysergamide and its derivatives: LSD, 1P-LSD, and AL-LAD. C Phenethylamine and its derivatives with psychedelic properties: mescaline, 2C-B, 25B-NBOMe, 25I-NBOMe, DOM, DOI, and BromoDragonFLY (see list of abbreviations for names of chemical compounds)

submitted samples in 2007, they accounted for $7.6 \%$ in 2013 [40] and $11 \%$ in 2017 [41*]. NPS incidence rates significantly increased in DC samples between 2013 and 2016 (7-15\%). DC samples involving NPS mainly contained 
phenethylamines in general between 2013 and 2017 (80\%), of which the psychedelic $2 \mathrm{C}$-x derivatives were the second most frequently detected within the group of phenethylamines throughout this period (17-36\%), with a significant increase between 2013 and 2016. Overall, DIMS detected 11 different tryptamines and 19 different psychedelic phenethylamines, including DOx, AMT, and NBOMes, between 2013 and $2017\left[41^{* *}\right.$ ]. Brunt and Niesink reported on the purity and content of psychedelic samples submitted to DIMS between 1999 and 2010 [5]. By far, the most prevalent SPs were LSD, followed by $2 \mathrm{C}-\mathrm{B}$. Other SPs were found on a sporadic basis, e.g. DMT, 5-MeO-DiPT, 2C-T-2, and 2C-T-7. The number of submitted LSD samples increased substantially from 6 samples in 1999 to 66 in the first half of 2010, whereas 2C-B was increasingly found in the second half of the $2000 \mathrm{~s}$, also in LSD and ecstasy samples. Between 1999 and 2010, around $80 \%$ of samples submitted as LSD contained LSD, with considerable annual variations. While in 2002, only $26 \%$ of samples contained LSD and the most prevalent adulterations were methamphetamine or DOB; in 2007, over $95 \%$ of samples contained LSD but some samples contained the very potent synthetic opioid fentanyl, prompting warning campaigns.

\section{Spain}

The DC service "Energy Control" reported a progressive increase in samples submitted as tryptamines between 2006 and 2015 [42*0]. Tryptamines accounted for $1.7 \%$ of all submitted samples $(n=25,296)$. About half of the tryptamine samples $(46.8 \%)$ were regulated and therefore illegal under Spanish law, namely DMT, psilocin, psilocybin, DET, or AET. The quality of regulated vs. unregulated tryptamine samples was relatively similar, with $62.7 \%$ vs. $64.7 \%$ containing the expected substance, $21.1 \%$ vs. $24.6 \%$ containing an additional psychoactive tryptamine, and $3.4 \%$ vs. $2.2 \%$ containing nontryptamine substances, respectively. However, $10.8 \%$ of regulated tryptamines contained no active substance, compared to $2.2 \%$ of unregulated tryptamines. The most prevalent substances found in samples were 4-AcO-DMT, which was patented by Hofmann and co-workers in 1963, with similar psychoactive properties like psilocybin, but largely unknown pharmacological characteristics [43, 44], followed by AMT, 5-MeO-DMT, 5-MeO-DiPT, and bufotenine (N,Ndimethylserotonin). One sample delivered as 5-MeO-MALT contained 25C-NBOMe. Between 2009 and 2012, "Energy Control" also reported an increase in the number of NPS adulterations in controlled substances [45]. Notably, the most frequently detected NPS adulterant was 2C-B, which was found especially often in MDMA tablets. Of the 173 adulterated samples, nine samples were sold as LSD (5.2\%) and two samples were sold as mescaline (1.2\%). Those samples were exclusively adulterated with novel SPs, namely NBOMes, 2C-x, and DOx. In 2014-2015, however, no adulterations were found in LSD samples bought from online cryptomarkets [46].

\section{UK}

Measham evaluated a stationary DC service in 2 cities in 2018 [47]. Of the 171 submitted samples, $12.2 \%$ were submitted as SPs, and in $14.6 \%$ of all submitted samples, SPs were detected. Identified SPs comprised LSD, 2C-B, DMT, mescaline, and $5-\mathrm{MeO}-\mathrm{MiPT}$ in addition to $25 \mathrm{C}-\mathrm{NBOH}$ and $25 \mathrm{D}-$ NBOMe mis-sold as LSD, prompting social media alerts. The on-site DC of "The Loop" at a UK festival in 2016 identified LSD in two samples $(0.9 \%)$ and NPS in three samples (1.3\%) among the 247 submitted samples [3]. Information on the individual purity of the samples is missing, except that $19.5 \%$ of all samples were mis-sold and that substances acquired at the festival were more than twice as likely to contain adulterations or analogues compared with those bought offsite $(27 \%$ vs. $12 \%)$.

\section{Canada}

At multiple music festivals and events in $2018,4.2 \%$ of the 336 samples submitted to an on-site DC service were expected to be SPs such as 2C-x, DMT, 4-AcO-DMT, and 4-HO-MET [48]. Among all categories of substances tested, multiple NPS were found, including the SP $2 \mathrm{C}-\mathrm{x}(\mathrm{n}=7)$ and 31 unknown substances.

\section{Portugal}

In contrast, $29.7 \%$ of 753 samples submitted to the on-site DC service at the 2016 electronic open-air festival "Boom" were expected to be SPs, with LSD being the second most tested substance at this festival after MDMA [4]. While all 2C-B samples were unadulterated, $11.6 \%$ of expected LSD samples contained an NBOMe or DOx and one sample of $2 \mathrm{C}-\mathrm{E}$ also contained an NBOMe. Martins et al. assessed the misrepresentation of LSD at the "Boom" festival in 2014, where a larger than expected proportion of alerts were disseminated compared to 2012 [49]. Of the 245 submitted LSD samples, $67.3 \%$ contained LSD only, $0.8 \%$ contained adulterations, and in $7.8 \%$ of the samples, no psychoactive substance was detected. However, $24.1 \%$ contained another psychoactive substance instead of LSD, e.g. DOx in $11.4 \%$ and NBOMes in $9.8 \%$.

\section{Italy}

Similar adulterations were found at 27 music events across Italy during 2016 and 2017 [50]. Among the 472 submitted samples, 18 (3.8\%) were identified as SPs, of which $13(2.8 \%)$ were NPS such as NBOMes, 2C-x, DOx, 5-MeO-MiPT, and 
4-AcO-MET. Each of those NPS was also found among the 10 mis-sold SPs samples $(2.1 \%)$, in addition to the mis-sold MDMA sample containing 5-MeO-MiPT. In 2019, however, no adulterations or analogues were found in the 4 SPs samples (2\%) submitted at 5 music events in Italy [51].

\section{Australia}

At an Australian festival, a study from 2005 reported an alleged presence of SPs in 5 adulterated ecstasy pills, but their analysis technique was insufficient to identify the specific substance [52].

\section{Belgium}

The Belgian DC service "Modus Vivendi" also reported the presence of 5-MeO-MiPT and N-Et-2,3-MDPEA among two of the 287 on-site samples sold as amphetamine, cocaine, or ketamine between 2018 and 2019 [53].

\section{Discussion}

In the present review investigating the presence and proportion of SPs in samples submitted to DC services, we report the following findings: Firstly, we found that SPs constitute a relatively low but increasing proportion of all submitted substances to DC services, with considerable variations between and across stationary and on-site services worldwide. Secondly, most DC services reported the presence of unexpected SPs in mis-sold (non-psychedelic) samples. Thirdly, adulterations or analogues containing novel SPs were also relatively common among all DC services. In contrast to synthetic and semi-synthetic SPs, plants or fungi like ayahuasca, peyote, and psilocybin ("magic mushrooms") were not reported to have been submitted to DC services.

While these findings are limited to peer-reviewed articles reporting data from different years and thus, not necessarily reflect the global situation, they are in line with data provided by the European Monitoring Centre for Drugs and Drug Addiction (EMCDDA) and the United Nations Office on Drugs and Crime (UNODC). Across all European DC services who report via the Trans European Drug Information (TEDI) network, LSD accounted for $9.4 \%$ and NPS in general for $3.9 \%$ of all submitted samples in the first half of 2018 [54]. During the first half of 2019, however, NPS in general accounted for $5 \%$ of all submitted DC samples [55]. Novel SPs, in particular 1P-LSD and 4-AcO-DMT, were the second most common NPS class detected after stimulants. Similarly, the UNODC stated that in December 2020, $15 \%$ of the 1047 recorded NPS belonged to the SPs class [56].
Considering the substantial number of submitted SPs and the relatively common detection of novel SPs by DC services, it is worth discussing the potential harms of novel SPs.

\section{Harms Associated with Serotonergic Psychedelics}

In general, it is well known that psychological aspects of psychedelic experiences highly depend on the interaction of the drug (e.g. dosage and effects), set (e.g. intention, preparation, and the characteristics of the individual), and setting (i.e. the environment) in which a substance is used [57]. This is especially relevant for SPs, given their potential to facilitate profound alterations of consciousness [34], intense feelings of suggestibility for external and internal influences [58-60], and enduring effects that outlast the acute action of the substances on the central nervous system [61]. While classic SPs are considered to be relatively safe when administered to healthy, high-functioning, and well-prepared study participants in a closely monitored research environment [35 $]$, recreational use may be associated with an increased risk of acute adverse reactions or subacute and long-term persisting adverse psychological effects $\left[35^{\circ}, 59\right]$, as discussed later. Of particular concern is the unintended ingestion of SPs, as multiple DC services reported the presence of SPs in mis-sold non-psychedelic samples $[5,45,50,52,53]$. Aside from the harms related to an inappropriate set and setting, there are substance-specific harms related to the physiological and psychological effects that also have to be considered.

In contrast to classic SPs, the acute toxicity and long-term health effects of novel SPs are often unknown. The most common novel SPs detected by DC services belong to the phenethylamine groups DOx, 2C-x, and NBOMes. While naturally occurring SPs are partial 5-HT2a agonists, some phenethylamine derivatives such as NBOMes exhibit full agonist action at 5-HT2a sites, which partly explains the toxicological profile due to increased potency and associated health risks such as the central serotonin syndrome [38]. There are anecdotal reports of serotonergic and sympathomimetic toxic effects, such as vomiting, diarrhoea, metabolic acidosis, mydriasis, vasoconstriction, hypertension, hyperthermia, muscle rigidity, agitation, convulsion, seizures, thrombocytopenia, rhabdomyolysis, renal or multi-organ failure, coma, and death [29, 62-64].

The intensity and frequency of those symptoms appear to be marked in novel N-benzylated phenethylamines, i.e. NBOMes [39]. A systematic review identified 70 cases of intoxication by NBOMes, of which 7 (10\%) were fatal [65]. Of special concern is the risk of overdosing due to the very high potency of NBOMes, which are nasally, sublingually, or buccally active at sub-milligramme dosages, similar to active dosages of LSD [66]. While the risk of overdosing is especially great when NBOMes are nasally insufflated, sublingual or buccal administration of blotter papers also increases the risk 
of overdosing, since it has been reported that some parts contained considerably higher quantities of 25I-NBOMe and 25C-NBOMe compared to other parts [67], which is problematic for correct dose determination. Apart from multiple fatalities due to NBOMes, namely 25I-NBOMe, 25B-NBOMe, and 25C-NBOMe (for a review, see [39]), fatalities have also been associated with other novel SPs, e.g. tryptamines (AMT, 5-MeO-AMT, AET, 5-OH-DMT [68]) and derivatives of the phenethylamine groups 2C-x (2C-E [69, 70], 2C-T-7, 2C-T21 [71]) and DOx (DOB, DOC [62, 72], Bromo-DragonFLY [73]) (see list of abbreviations). Even if the exact toxicological mechanisms are not well understood in humans, animal studies indicate neuro- and genotoxic properties of certain SPs, such as 5-MeO-DIPT [74], 2C-C, 2C-P [75], and 25BNBOMe $[76,77]$. In the case of $2 \mathrm{C}-\mathrm{B}$, poisonings reported to the Dutch Poisons Information Centre were mild to moderate [64] according to the Poisoning Severity Score [78], but severe neurological reactions to $2 \mathrm{C}-\mathrm{B}$ have also been reported, i.e. central serotonin syndrome, epileptic seizures, cerebral oedema [79], and cerebral vasculopathy [80]. These aspects are of high relevance, as $2 \mathrm{C}-\mathrm{B}$ is currently the third most popular SP in recreational users, following LSD and psilocybin [17].

In most cases, however, physical risks of SPs are not due to the general toxicity of the substance, but rather to the profound and sometimes overwhelming psychological effects that can lead to accidents and other harmful and potentially fatal behaviours. Acute adverse psychological effects include dysphoria, panic, confusion, hallucinations, paranoid thought, aggression, and anxiety $[38,64]$. These symptoms could be especially problematic by using long-acting phenethylamine psychedelics like DOB and DOI, with effects lasting for up to $36 \mathrm{~h}$ [81], or in cases of unintended consumption of SPs due to mis-sold non-psychedelic samples. Of concern are recent incidences of LSD poisonings following insufflation of a white powder mis-sold as cocaine [82]. Four subjects required hospitalisation showing clinical features of hallucinations, agitation, vomiting, sedation, hypertension, and mydriasis, but were discharged without persistent injury. Another major concern are the unpredictable physiological and psychological effects of polydrug use, as it is especially common at music events and festivals [83]. The concomitant use of other serotonergic substances, e.g. selective serotonin reuptake or monoamine oxidase inhibitors, could further increase the risk of serotonergic toxicity [84]. Also, the concomitant use of other substance classes, either intentionally or unintentionally due to adulterations, could be a health risk since LSD has been shown to potentiate the neurotoxic effect of MDMA in animals [85]. Notably, in addition to the acute effects and risks of SPs, there are also several reports of subacute and long-term persisting adverse psychological effects associated with their recreational use, including psychosis [86], hallucinogen persisting perception disorder (HPPD) [87], and depersonalisation/derealisation syndrome (DDS) [88], especially emphasising risks and potential consequences of unintended ingestion as mis-sold substances or adulterants by unprepared users.

Taken together, physical and psychological harms of both classic and novel SPs to the user can be reduced by considering the purity and, if possible, the dosage of the substance as well as ensuring an appropriate set and setting for use. As the acute and long-term health effects of novel SPs are generally not known and could potentially be life-threatening, DC is a valuable tool for reducing risks by detecting SPs in samples bought as SPs or in other non-SPs samples, since unintended ingestion under inappropriate conditions is associated with major risks in this group of substances. However, the detection of SPs by DC services comes with certain hurdles and challenges.

\section{Challenges for Drug Checking in Reducing Psychedelic-Related Harm}

First and foremost, the extent of harm reduction relies on the accuracy and reliability of the analysis results $\left[7^{\circ}\right]$. The detection and quantification of SPs require the use of analysis techniques with high sensitivity, like hyphenated techniques, involving liquid or gas chromatography and mass spectrometry (MS), in addition to the use of reference standards for quantification purposes $\left[8^{\circ}\right]$. These analysis techniques are usually costly and often limited to stationary DC services due to the equipment required. If DC services are, nevertheless, able to provide such analysis on-site, an adequate counselling and communication of the results to the potential substance user must be ensured even in a noisy and distracting party environment.

An analytical challenge is also presented by the substantial number of novel SPs, for which the reference standards or mass spectrum of recently evolved substances may not be available in libraries, so substances' identification may be missed [68]. As not all DC services have the means to quantify SPs with MS, qualitative techniques such as Fourier transform infrared (FTIR) spectroscopy [48], Raman spectroscopy (RS) [50], low-voltage paper spray ionisation quadrupole time-offlight (QTOF)-MS [90], thin-layer chromatography (TLC), or colorimetric reagent tests [4] may be used at least for qualitative analysis, i.e. to detect the presence or absence of a component. Unlike the least precise colorimetric reagent tests, the aforementioned technologies are relatively expensive and sometimes require a laboratory. In spite of their limited sensitivity, portable RS and FTIR have a good specificity for detecting the most abundant molecules on-site, but not necessarily adulterants or cutting agents [89"].

If jurisprudential challenges in some countries may not allow organisations or safer nightlife projects to analyse substances, as it usually involves the possession of an illegal 
substance, potential legal risks could be prevented with the use of RS since substance contact by personnel is not required. Furthermore, advice could be given regarding problematic indications (e.g. bitter taste and sublingual numbing caused by NBOMes [91]), and less precise strategies could be employed such as the use of ultraviolet (UV) light to detect LSD, as it exhibits fluorescence under UV excitation [92]. However, given the limited sensitivity and specificity of qualitative analysis techniques and the associated harms thereof, such DC services need to inform potential substance users about these limitations and should consider a collaboration with laboratories to ensure detection, quantification, and monitoring of substances, including SPs.

\section{Conclusions}

The increasing interest in serotonergic psychedelics (SPs) and the potential risks and harms associated with the use of classic and novel SPs justify efforts to establish advanced analysis techniques. If such techniques are not available, DC services should aim to collaborate with laboratories to provide detection and quantification of SPs, thereby also contributing to effective market monitoring. Despite the comparably low submission rate of SPs to DC services and the considerable cost of their analyses, DC services are also valuable tools for raising awareness on the risk of SPs adulterations in non-psychedelic drug samples, the potential harm associated with SPs use in general, and with novel SPs in particular, and corresponding harm minimisation strategies for otherwise hard-to-reach substance user communities. More specifically, detection of SPs might be especially useful with regard to certain novel synthetic phenethylamine psychedelics such as NBOMes, which have been detected in samples sold as LSD or MDMA, exhibiting a higher level of toxicity and sometimes unpredictably prolonged durations of action. Despite these opportunities for DC to reduce the SP-related harm to recreational substance users, DC should be incorporated in a well-informed comprehensive drug approach required to deal with this public health concern.

Abbreviations 1P-LSD, 1-propionyl-d-LSD; 25B-NBOMe, 2-(4-bromo-2,5-dimethoxyphenyl)-N-(2-methoxybenzyl)ethanamine; $25 \mathrm{C}$ NBOMe, 2-(4-chloro-2,5-dime thoxypheny 1$)-\mathrm{N}-(2-$ methoxybenzyl)ethanamine; 25D-NBOMe, 2-(4-methyl-2,5dimethoxyphenyl)-N-2-(methoxybenzyl)ethanamine; 25I-NBOMe , 2-(4-iodo-2,5-dimethoxyphenyl)-N-(2-methoxybenzyl)ethanamine; $2 \mathrm{C}$ $\mathrm{B}$, 4-bromo-2,5-dimethoxy-4-bromo-phenethylamine; 2C-C, 4-chloro2,5-dimethoxyphenethylamine; $2 \mathrm{C}$ - $\mathrm{H}, 2,5$-dimethoxyphenethylamine; 2C-I, 4-iodo-2,5-dimethoxyphenethylamine; 2C-P, 4-propyl-2,5dimethoxyphenethylamine; $2 \mathrm{C}-\mathrm{T}-2,4$-ethylthio- 2,5 dimethoxyphenethylamine; 2C-T-21, 4-(2-fluoroehtylthio)-2,5dimethoxyphenethylamine; $2 \mathrm{C}-\mathrm{T}-7,4$-propylthio-2,5dimethoxyphenethylamine; 4-AcO-DMT, 4-acetoxy-N,N- dimethyltryptamine; 4-AcO-MET, 4-acetoxy-N-ethyl-Nmethyltryptamine; 4-HO-MET, 4-hydroxy-N-ethyl-N-methyltryptamine; 5-MeO-AMT, 5-methoxy- $\alpha$-methyltryptamine; 5-MeO-DiPT, $5-$ methoxy-diisopropyltryptamine; 5-MeO-DMT, 5-methoxy-dimethyltryptamine; 5-MeO-MALT, 5-methoxy-N-methyl-N-allyltryptamine; 5MeO-MiPT, 5-methoxy-N-methyl-N-isopropyltryptamine; AET, $\alpha$ ethyltryptamine; AL-LAD, 6-allyl-6-nor-lysergic acid diethylamide; AMT , $\alpha$-methyltryptamine; Bromo-DragonFLY, 8-bromo-4-(2aminopropyl)benzodifuran; DC, drug checking; DDS, depersonalisation/derealisation syndrome; DET, N,N-diethyltryptamine; DIMS, Drugs Information and Monitoring System; DMT, N,N-dimethyltryptamine; DOB, 2,5-dimethoxy-4-bromoamphetamine; DOC, 4chloro-2,5-dimethoxyamphetamine; DOI, 2,5-dimethoxy-4iodoamphetamine; EMCDDA, European Monitoring Centre for Drugs and Drug Addiction; FTIR, Fourier transform infrared spectroscopy; HPPD, hallucinogen persisting perception disorder; LSD, lysergic acid diethylamide; MDMA, 3,4-methylenedioxymethamphetamine; MS, mass spectrometry; N-Et-2,3-MDPEA, N-ethyl-2,3methylenedioxyphenetylamine; NPS, new psychoactive substances; QTOF, low-voltage paper spray ionisation quadrupole time-of-flight; RS, Raman spectroscopy; TEDI, Trans European Drug Information; TLC, thin-layer chromatography; UK, United Kingdom; UNODC, United Nations Office on Drugs and Crime; UV, ultraviolet

Funding Open Access funding enabled and organized by Projekt DEAL.

\section{Declarations}

Conflict of Interest The authors declare no competing interests.

Human and Animal Rights and Informed Consent This article does not contain any studies with human or animal subjects performed by any of the authors.

Open Access This article is licensed under a Creative Commons Attribution 4.0 International License, which permits use, sharing, adaptation, distribution and reproduction in any medium or format, as long as you give appropriate credit to the original author(s) and the source, provide a link to the Creative Commons licence, and indicate if changes were made. The images or other third party material in this article are included in the article's Creative Commons licence, unless indicated otherwise in a credit line to the material. If material is not included in the article's Creative Commons licence and your intended use is not permitted by statutory regulation or exceeds the permitted use, you will need to obtain permission directly from the copyright holder. To view a copy of this licence, visit http://creativecommons.org/licenses/by/4.0/.

\section{References}

Papers of particular interest, published recently, have been highlighted as:

- Of importance

•. Of major importance

1. Hungerbuehler I, Buecheli A, Schaub M. Drug checking: a prevention measure for a heterogeneous group with high consumption frequency and polydrug use - evaluation of Zurich's drug checking services. Harm reduction journal. Springer Science and Business Media LLC, BioMed Central Ltd, BMC; 2011;8:16-16. 
2. Fernández-Calderón F, Lozano-Rojas Ó, Rojas-Tejada A, BilbaoAcedos I, Vidal-Giné C, Vergara-Moragues E, et al. Harm reduction behaviors among young polysubstance users at raves. Substance Abuse Taylor \& Francis; 2014;35:45-50.

3. Measham FC. Drug safety testing, disposals and dealing in an English field: exploring the operational and behavioural outcomes of the UK's first onsite 'drug checking' service. Int J Drug Policy. 2019;67:102-7.

4. Valente H, Martins D, Carvalho H, Pires CV, Carvalho MC, Pinto $\mathrm{M}$, et al. Evaluation of a drug checking service at a large scale electronic music festival in Portugal. Int J Drug Policy. 2019;73: 88-95.

5. Brunt TM, Niesink RJ. The Drug Information and Monitoring System (DIMS) in the Netherlands: implementation, results, and international comparison. Drug testing and analysis. Wiley Online Library; 2011;3:621-634.

6. Betzler F, Helbig J, Viohl L, Ernst F, Roediger L, Gutwinski S, et al. Drug checking and its potential impact on substance use. EAR Karger Publishers; 2021;27:25-32.

7. Brunt T. Drug checking as a harm reduction tool for recreational drug users: opportunities and challenges. 2017. This is an important contribution on the conceptual understanding of drug checking and the opportunities and challenges drug checking provides.

8. King LA, Sedefov R. Early-warning system on new psychoactive substances. 2007.

9. Barratt MJ, Kowalski M, Maier LJ, Ritter A. Global review of drug checking services operating in 2017. Drug policy modelling program bulletin. National Drug and Alcohol Research Center, UNSW; 2018;24.

10. United Nations Office on Drugs and Crime. Cross-cutting issues: evolving trends and new challenges [Internet]. United Nations : World Drug Report 2020. 2020 [cited 2021 Mar 29]. Available from: //wdr.unodc.org/wdr2020/en/cross-cutting.html

11. Palamar JJ, Salomone A. Shifts in unintentional exposure to drugs among people who use ecstasy in the electronic dance music scene, 2016-2019. Am J Addict. 2021;30:49-54.

12. Vogels N, Brunt TM, Rigter S, Dijk PV, Vervaeke H, Niesink RJM. Content of ecstasy in the Netherlands: 1993-2008. Addiction. 2009;104:2057-66.

13. Nichols DE, Johnson MW, Nichols CD. Psychedelics as medicines: an emerging new paradigm. Clinical Pharmacology \& Therapeutics Wiley Online Library; 2017;101:209-219.

14. European Monitoring Centre for Drugs and Drug Addiction. European drug report 2020: trends and developments. [Internet]. LU: Publications Office; 2020 [cited 2021 Mar 11]. Available from: https://data.europa.eu/doi/10.2810/420678

15. Palamar JJ, Le A. Trends in DMT and other tryptamine use among young adults in the United States. Am J Addict. 2018;27:578-85.

16. Palamar JJ, Le A. Use of new and uncommon synthetic psychoactive drugs among a nationally representative sample in the United States, 2005-2017. Hum Psychopharmacol. 2019;34:e2690.

17. Winstock AR, Timmerman C, Davies E, Maier LJ, Zhuparris A, Ferris JA, et al. Global drug survey (GDS) 2020 psychedelics key findings report. [Internet]. London: Global Drug Survey; 2021 Mar. Available from: https://www.globaldrugsurvey.com/

18. Yockey RA, Vidourek RA, King KA. Trends in LSD use among US adults: 2015-2018. Drug Alcohol Depend. 2020;212:108071.

19. Yockey A, King K. Use of psilocybin ("mushrooms") among US adults: 2015-2018. Journal of Psychedelic Studies. 2021;5:17-21.

20. Betzler F, Ernst F, Helbig J, Viohl L, Roediger L, Meister S, et al. Substance use and prevention programs in Berlin's party scene: results of the SuPrA-study. Eur Addict Res. 2019;25:283-92.

21. Vollenweider FX. Vollenweider-Scherpenhuyzen MFI, Bäbler A, Vogel H, Hell D. Psilocybin induces schizophrenia-like psychosis in humans via a serotonin-2 agonist action. NeuroReport. 1998;9: 3897-902.

22. Nichols DE. Chemistry and structure-activity relationships of psychedelics. Curr Top Behav Neurosci. 2018;36:1-43.

23. Liechti ME. Modern clinical research on LSD. Neuropsychopharmacol. 2017;42:2114-27.

24. Schultes RE, Hofmann A. Plants of the gods: origins of hallucinogenic use. McGraw-Hill New York; 1979.

25. United Nations Office on Drugs and Crime. The challenge of new psychoactive substances. 2013.

26. Kousara S, Anjuma SN, Jaleela F, Khana J, Naseema S. Biomedical significance of tryptamine: a review. Journal of Pharmacovigilance. 2017;5:1-6.

27. Nichols DE. Structure-activity relationships of serotonin 5-HT2A agonists. Wiley Interdisciplinary Reviews: Membrane Transport and Signaling 2012;1:559-579.

28. Nichols DE, Fantegrossi WE. Emerging designer drugs. In: Madras $\mathrm{B}$, Kuhar M, editors. The effects of drug abuse on the human nervous system. Boston: Academic Press; 2014. p. 575-96.

29. Halberstadt AL. Pharmacology and toxicology of Nbenzylphenethylamine ("NBOMe") hallucinogens. Curr Top Behav Neurosci. 2017;32:283-311. This review provides a detailed description on the pharmacology and toxicology of NBOMes, which are commonly detected as adulterants or analogues in drug checking samples and, therefore, constitute a public health concern due to its toxicity.

30. Poulie CBM, Jensen AA, Halberstadt AL, Kristensen JL. DARK classics in chemical neuroscience: NBOMes. ACS Chem Neurosci. 2019;11:3860-9.

31. Wolbach AB, Miner EJ, Isbell H. Comparison of psilocin with psilocybin, mescaline and LSD-25. Psychopharmacologia. 1962;3:219-23.

32. Hollister LE, Hartman AM. Mescaline, lysergic acid diethylamide and psilocybin: comparison of clinical syndromes, effects on color perception and biochemical measures. Compr Psychiatry. 1962;3: 235-41.

33. Zamberlan F, Sanz C, Martinez Vivot R, Pallavicini C, Erowid F, Erowid E, et al. The varieties of the psychedelic experience: a preliminary study of the association between the reported subjective effects and the binding affinity profiles of substituted phenethylamines and tryptamines. Front Integr Neurosci. 2018;12:54

34. Hirschfeld T, Schmidt TT. Dose response relationships of psilocybin-induced subjective experiences in humans. J Psychopharmacol. SAGE Publications Ltd STM. 2021;35:384-97.

35. Nichols DE. Psychedelics. Pharmacol Rev. 2016;68:264-355. This review provides a comprehensive overview of classic and novel psychedelic substances and their historical use, issues of safety and mental health in psychedelic users, mechanism of action and potential as therapeutic agents.

36. European Monitoring Centre for Drugs and Drug Addiction. New psychoactive substances: global markets, global threats and the COVID 19 pandemic : an update from the EU early warning system. [Internet]. LU: Publications Office; 2020 [cited 2021 Mar 29]. Available from: https://data.europa.eu/doi/10.2810/921262

37. United Nations Office on Drugs and Crime. Current NPS threats [Internet]. United Nations : Office on Drugs and Crime. 2020 [cited 2021 Mar 13]. Available from: //www.unodc.org/unodc/en/ scientists/current-nps-threats.html

38. Schifano F, Chiappini S, Miuli A, Corkery JM, Scherbaum N, Napoletano F, et al. New psychoactive substances (NPS) and serotonin syndrome onset: a systematic review. Exp Neurol. 2021;339: 113638.

39. Zawilska JB, Kacela M, Adamowicz P. NBOMes-Highly potent and toxic alternatives of LSD. Front Neurosci. 2020;14:78. 
40. Hondebrink L, Nugteren-van Lonkhuyzen JJ, Van Der Gouwe D, Brunt TM. Monitoring new psychoactive substances (NPS) in the Netherlands: data from the drug market and the Poisons Information Centre. Drug Alcohol Depend. 2015;147:109-15.

41.• Hondebrink L, Nugteren-van Lonkhuyzen JJ, Hunault CC, van den Berg J, van der Gouwe D, van Riel AJHP. New psychoactive substances (NPS) in the Netherlands: occurrence in forensic drug samples, consumer drug samples and poisons center exposures between 2013 and 2017. Addiction. 2020;115:716-25. This national observational study provides the latest data on NPS in drug checking samples in the Netherlands, with detailed information on analysed substances per year between 2013 and 2017.

42.• Palma-Conesa ÁJ, Ventura M, Galindo L, Fonseca F, Grifell M, Quintana P, et al. Something new about something old: a 10-year follow-up on classical and new psychoactive tryptamines and results of analysis. Journal of psychoactive drugs. Taylor \& Francis; 2017;49:297-305. This study provides data on the detection of classic and novel tryptamines in drug checking samples in Spain. Detailed information on the specific compounds and trends over a 10-year time span are valuable in the assessment of the relevance of tryptamines for drug checking services.

43. Chadeayne AR, Golen JA, Manke DR. The crystal structure of 4AcO-DMT fumarate [Internet]. Psychedelic Science Review. 2019 [cited 2021 March 31]. Available from: https://psychedelicreview. com/the-crystal-structure-of-4-aco-dmt-fumarate/.

44. Hofmann A, Troxler F. Esters of indoles. US3075992A. January 1963. 1963.

45. Giné CV, Espinosa IF, Vilamala MV. New psychoactive substances as adulterants of controlled drugs. A worrying phenomenon? Drug Test Anal. 2014;6:819-24.

46. Caudevilla F, Ventura M, Fornís I, Barratt MJ, Vidal C, lladanosa $\mathrm{CG}$, et al. Results of an international drug testing service for cryptomarket users International Journal of Drug Policy 2016;35: 38-41.

47. Measham F. City checking: piloting the UK's first communitybased drug safety testing (drug checking) service in 2 city centres. British journal of clinical pharmacology. England; 2020;86:420 428.

48. McCrae K, Tobias S, Tupper K, Arredondo J, Henry B, Mema S, et al. Drug checking services at music festivals and events in a Canadian setting. Drug Alcohol Depend. 2019;205:107589.

49. Martins D, Barratt MJ, Pires CV, Carvalho H, Vilamala MV, Espinosa IF, et al. The detection and prevention of unintentional consumption of DOx and 25x-NBOMe at Portugal's Boom Festival. Hum Psychopharmacol Clin Exp. 2017;32:e2608.

50. Gerace E, Seganti F, Luciano C, Lombardo T, Di Corcia D, Teifel $\mathrm{H}$, et al. On-site identification of psychoactive drugs by portable Raman spectroscopy during drug-checking service in electronic music events. Drug and alcohol review. Melbourne: Wiley, John Wiley \& Sons Australia, Ltd, Wiley Subscription Services. Inc. 2019;38:50-6.

51. Fregonese M, Albino A, Covino C, Gili A, Bacci M, Nicoletti A, et al. Drug checking as strategy for harm reduction in recreational contests: evaluation of two different drug analysis methodologies. Front Psychiatry. 2021;12:596895.

52. Camilleri AM, Caldicott D. Underground pill testing, down under. Forensic Sci Int. 2005;151:53-8.

53. Deconinck E, Aït-Kaci C, Raes A, Canfyn M, Bothy J-L, Duchateau C, et al. An infrared spectroscopic approach to characterise white powders, easily applicable in the context of drug checking, drug prevention and on-site analysis. Drug Test Anal. 2021;13:679-93.

54. European Monitoring Centre for Drugs and Drug Addiction. European drug report 2019: trends and developments. [Internet]. LU: Publications Office; 2019 [cited 2021 Mar 31]. Available from: https://data.europa.eu/doi/10.2810/191370
55. European Monitoring Centre for Drugs and Drug Addiction. European drug report 2020: trends and developments. [Internet]. LU: Publications Office; 2020 [cited 2021 Mar 31]. Available from: https://data.europa.eu/doi/10.2810/420678

56. United Nations Office on Drugs and Crime. News: February 2021 UNODC EWA: share of NPS stimulants and synthetic cannabinoids remains stable while opioids continue to increase [Internet]. 2021 [cited 2021 Mar 13]. Available from: https://www.unodc.org/ LSS/Announcement/Details/d45a4db1-4f64-447e-818c$35 \mathrm{ce} 7 \mathrm{a} 2 \mathrm{e} 2278$

57. Zinberg NE. Drug, set, and setting: the basis for controlled intoxicant use: Yale University Press New Haven; 1984.

58. Aday JS, Davis AK, Mitzkovitz CM, Bloesch EK, Davoli CC. Predicting reactions to psychedelic drugs: a systematic review of states and traits related to acute drug effects. ACS Pharmacol Transl Sci. 2021b;4:424-35.

59. Carhart-Harris RL, Roseman L, Haijen E, Erritzoe D, Watts R, Branchi I, et al. Psychedelics and the essential importance of context. J Psychopharmacol. 2018;32:725-31.

60. Hartogsohn I. Constructing drug effects: a history of set and setting. Drug Science, Policy and Law. SAGE Publications; 2017;3: 2050324516683325.

61. Majić T, Schmidt TT, Gallinat J. Peak experiences and the afterglow phenomenon: when and how do therapeutic effects of hallucinogens depend on psychedelic experiences? J Psychopharmacol SAGE Publications Ltd STM; 2015;29:241-253.

62. Balíková M. Nonfatal and fatal DOB (2, 5-dimethoxy-4bromamphetamine) overdose. Forensic science international. Elsevier. 2005;153:85-91.

63. Costa G, De Luca MA, Piras G, Marongiu J, Fattore L, Simola N. Neuronal and peripheral damages induced by synthetic psychoactive substances: an update of recent findings from human and animal studies. Neural regeneration research. Wolters KluwerMedknow Publications; 2020;15:802.

64. Nugteren-van Lonkhuyzen JJ, de Lange DW, van Riel AJHP, Vrolijk RQ, Ohana D, Hondebrink L. The clinical toxicology of 4-bromo-2,5-dimethoxyphenethylamine (2C-B): the severity of poisoning after exposure to low to moderate and high doses. Ann Emerg Med. 2020;76:303-17.

65. Marchi NC, Scherer JN, Fara LS, Remy L, Ornel R, Reis M, et al. Clinical and toxicological profile of NBOMes: a systematic review. Psychosomatics. 2019;60:129-38.

66. Pottie E, Cannaert A, Stove CP. In vitro structure-activity relationship determination of 30 psychedelic new psychoactive substances by means of $\beta$-arrestin 2 recruitment to the serotonin $2 A$ receptor. Archives of Toxicology Springer; 2020;94:3449-3460.

67. Lützen E, Holtkamp M, Stamme I, Schmid R, Sperling M, Pütz M, et al. Multimodal imaging of hallucinogens 25C- and 25I-NBOMe on blotter papers. Drug Test Anal. 2020;12:465-71.

68. Malaca S, Lo Faro AF, Tamborra A, Pichini S, Busardò FP, Huestis MA. Toxicology and analysis of psychoactive tryptamines. Int J Mol Sci. 2020;21.

69. Topeff JM, Ellsworth H, Willhite LA, Bangh SA, Edwards EM, Cole JB. A case series of symptomatic patients, including one fatality, following 2C-E exposure. Clinical Toxicology. Informa healthcare 52 vanderbilt ave, New York, NY 10017 USA; 2011. p. 526.

70. Van Vrancken MJ, Benavides R, Wians Jr FH. Identification of designer drug 2C-E (4-ethyl-2, 5-dimethoxyphenethylamine) in urine following a drug overdose. Baylor University Medical Center Proceedings. Taylor \& Francis; 2013;26:58-61.

71. Dean BV, Stellpflug SJ, Burnett AM, Engebretsen KM. 2C or not 2C: phenethylamine designer drug review. J Med Toxicol. 2013;9: 172-8.

72. Barnett RY, Baker DD, Kelly NE, McGuire CE, Fassette TC, Gorniak JM. A fatal intoxication of 2, 5-dimethoxy-4- 
chloroamphetamine: a case report. Journal of Analytical Toxicology. Oxford University Press; 2014;38:589-591.

73. Andreasen M, Telving R, Birkler RI, Schumacher B, Johannsen M. A fatal poisoning involving Bromo-Dragonfly. Forensic Sci Int. 2009;183:91-6.

74. Noworyta-Sokołowska K, Kamińska K, Rzemieniec J, Wnuk A, Wojcieszak J, Górska AM, et al. Effects of exposure to 5-MeODIPT during adolescence on brain neurotransmission and neurotoxicity in adult rats. Forensic Toxicol. 2019;37:45-58.

75. Kim YJ, Ma SX, Hur KH, Lee Y, Ko YH, Lee BR, et al. New designer phenethylamines $2 \mathrm{C}-\mathrm{C}$ and $2 \mathrm{C}-\mathrm{P}$ have abuse potential and induce neurotoxicity in rodents. Arch Toxicol. 2021;95: 1413-29.

76. Cocchi V, Gasperini S, Hrelia P, Tirri M, Marti M, Lenzi M. Novel psychoactive phenethylamines: impact on genetic material. Int $\mathrm{J}$ Mol Sci. 2020;21:9616.

77. Wojtas A, Herian M, Skawski M, Sobocińska M, González-Marín A, Noworyta-Sokołowska K, et al. Neurochemical and behavioral effects of a new hallucinogenic compound 25B-NBOMe in rats. Neurotox Res. 2021;39:305-26.

78. Persson HE, Sjöberg GK, Haines JA, Garbino JP de. Poisoning severity score. Grading of acute poisoning. Journal of Toxicology: Clinical Toxicology. Taylor \& Francis; 1998;36: 205-213.

79. Spoelder AS, Louwerens JKG, Krens SD, Jager N, LeCouffe NE, de Ruijter W, et al. Unexpected serotonin syndrome, epileptic seizures, and cerebral edema following 2,5-dimethoxy-4bromophenethylamine ingestion. J Forensic Sci. 2019;64:1950-2.

80. Ambrose JB, Bennett HD, Lee HS, Josephson SA. Cerebral vasculopathy after 4-bromo-2,5-dimethoxyphenethylamine ingestion. Neurologist. 2010;16:199-202.

81. Palamar JJ, Acosta P. A qualitative descriptive analysis of effects of psychedelic phenethylamines and tryptamines. Human Psychopharmacology: Clinical and Experimental. Wiley Online Library; 2020;35:e2719.

82. Roberts DM, Premachandra KH, Chan BS, Auld R, Jiranantakan T, Ewers C, et al. A cluster of lysergic acid diethylamide (LSD) poisonings following insufflation of a white powder sold as cocaine. Clin Toxicol (Phila). 2021;1-6.

83. Mohr ALA, Friscia M, Yeakel JK, Logan BK. Use of synthetic stimulants and hallucinogens in a cohort of electronic dance music festival attendees. Forensic Sci Int. 2018;282:168-78.

84. Bruggeman C, O'Day CS. Selective serotonin reuptake inhibitor toxicity. StatPearls [Internet]. Treasure Island (FL): StatPearls
Publishing; 2021 [cited 2021 Mar 31]. Available from: http:// www.ncbi.nlm.nih.gov/books/NBK534815/

85. Armstrong BD, Paik E, Chhith S, Lelievre V, Waschek JA, Howard SG. Potentiation of (DL)-3, 4-methylenedioxymethamphetamine (MDMA)-induced toxicity by the serotonin $2 \mathrm{~A}$ receptior partial agonist d-lysergic acid diethylamide (LSD), and the protection of same by the serotonin $2 \mathrm{~A} / 2 \mathrm{C}$ receptor antagonist MDL 11,939. Neuroscience Research Communications Wiley Online Library; 2004;35:83-95.

86. Vardy MM, Kay SR. LSD psychosis or LSD-induced schizophrenia?: a multimethod inquiry. Archives of General Psychiatry. American Medical Association; 1983;40:877-883.

87. Hermle L, Simon M, Ruchsow M, Geppert M. Hallucinogenpersisting perception disorder. Therapeutic advances in psychopharmacology. SAGE Publications Sage UK: London. England. 2012;2:199-205.

88. Simeon D, Kozin DS, Segal K, Lerch B. Is depersonalization disorder initiated by illicit drug use any different? A survey of 394 adults. The Journal of clinical psychiatry. Physicians Postgraduate Press, Inc.; 2009;70:1358-64.

89. Palamar JJ, Salomone A, Barratt MJ. Drug checking to detect fentanyl and new psychoactive substances. Curr Opin Psychiatry. 2020;33:301-5. This important review provides an overview of the latest analysis techniques available for substances like serotonergic psychedelics and describes challenges associated with their detection and quantification, in addition to adulteration rates and behavioural responses to analysis results.

90. Birk L, Franco de Oliveira S, Mafra G, Brognoli R, Carpes M, Scolmeister D, et al. A low-voltage paper spray ionization QTOFMS method for the qualitative analysis of NPS in street drug blotter samples. Forensic Toxicology. 2019;38.

91. Bersani FS, Corazza O, Albano G, Valeriani G, Santacroce R, Bolzan Mariotti Posocco F, et al. 25C-NBOMe: preliminary data on pharmacology, psychoactive effects, and toxicity of a new potent and dangerous hallucinogenic drug. BioMed research international. 2014;2014:734749.

92. Upshall DG, Wailling DG. The determination of LSD in human plasma following oral administration. Clinica Chimica Acta Elsevier; 1972;36:67-73.

Publisher's Note Springer Nature remains neutral with regard to jurisdictional claims in published maps and institutional affiliations. 